\title{
Moving towards same-day provision of Level 3 care in sexual and reproductive health services
}

\author{
Ulrike Sauer, ${ }^{1}$ Susan Mann, ${ }^{2}$ Judith M Stephenson ${ }^{3}$
}

- Additional material is published online only. To view please visit the journal online (http://dx.doi.org/10.1136/ bmjsrh-2017-101817).

${ }^{1}$ Central and North West London NHS Foundation Trust, Margaret Pyke Centres, London, UK ${ }^{2}$ Homerton University Hospital NHS Foundation Trust, Sexual and Reproductive Health (SRH), London, UK

${ }^{3}$ Research Department of Reproductive Health, Institute for Women's Health, London, UK

\section{Correspondence to} Dr Ulrike Sauer, Central and North West London NHS Foundation Trust, Margaret Pyke Centres, London NW10 8RX, UK; ulrike.sauer@nhs.net

Received 3 May 2017 Revised 19 January 2018 Accepted 25 January 2018 Published Online First 26 February 2018
Check for updates

To cite: Sauer U, Mann S, Stephenson JM. BMJ Sex Reprod Health

2018;44:299-302.

\section{BACKGROUND}

We describe a simple quality improvement project leading to a change in the configuration of referral pathways within the sexual and reproductive health (SRH) service at Margaret Pyke Centre (MPC), London, UK. This service provides open access to contraception. In 2015 the MPC provided services for 14604 patients. Some $39 \%$ of the patients were from the local boroughs of Camden and Islington, and 92\% came from all London boroughs and were equally distributed among all deprivation scores. The majority (68\%) of patients are white and $78 \%$ of all patients are aged between 21 and 35 years. While $95 \%$ of patients have their needs met in a single visit, $5 \%$ require onward referral to a Level 3 specialist clinic as specified in the Framework for Sexual Health Improvement in England. ${ }^{1}$ This accounts for about 150 patients per month, and due to the high demand women often wait up to 8 weeks for an appointment. In general it is known that "most dissatisfaction with the Health Service is due to long waiting times, staff shortages and lack of funding". ${ }^{2}$ Patients who wait for a long time are less likely to keep their appointments. ${ }^{34}$

Many of the women who require referral at MPC could be managed in a single visit if same-day specialist care with an ultrasound scan carried out by a trained specialist was available. This project was therefore designed to determine whether same-day access to specialist SRH care improves efficiency, reduces rates of failure to keep appointments (DNA: did not attend) and improves patient experience. The project was based on PDSA (Plan Do Study Act) methodology ${ }^{5}$ where a small change is put into place; it is studied and then modified to address the findings. The idea was to implement same-day Level 3 service provision within
MPC, modify change to the service as necessary, and evaluate the outcomes in terms of acceptability, feasibility and desirability for both staff and patients.

\section{WHAT WAS THE USUAL PATHWAY?}

The MPC is an integrated one-hub sexual health service with several satellite clinics. Women are seen in the general clinic and internal referrals are usually made through the electronic patient record system (EPR) from any location within the service. Patients are contacted with an appointment, often more than once, until the appointment is confirmed by the patient. If symptoms become worse or if there are ongoing worries, women frequently contact the clinic or re-attend the walk-in service while waiting for their booked appointment. An audit of the service, which investigated reasons for referring to Level 3, suggested that $90 \%$ of women referred could have been managed on the same day if this option was available.

\section{WHAT CHANGES WERE MADE?}

Instead of referring women via the EPR, patients were referred via telephone call to the administration staff. They were booked directly into the referral clinic and asked to wait in the clinic for their consultation.

The planned change was intended to reduce the administrative burden for patients, additional appointments and patient contact, and the need for interim contraception, by managing as many patients as possible for their specialist referral on the same day as their initial clinic visit. Evaluation of this project was conducted through assessment of waiting times, DNA rates and staff satisfaction before and after implementation of the change.

The project was based on a co-design methodology where close communication 


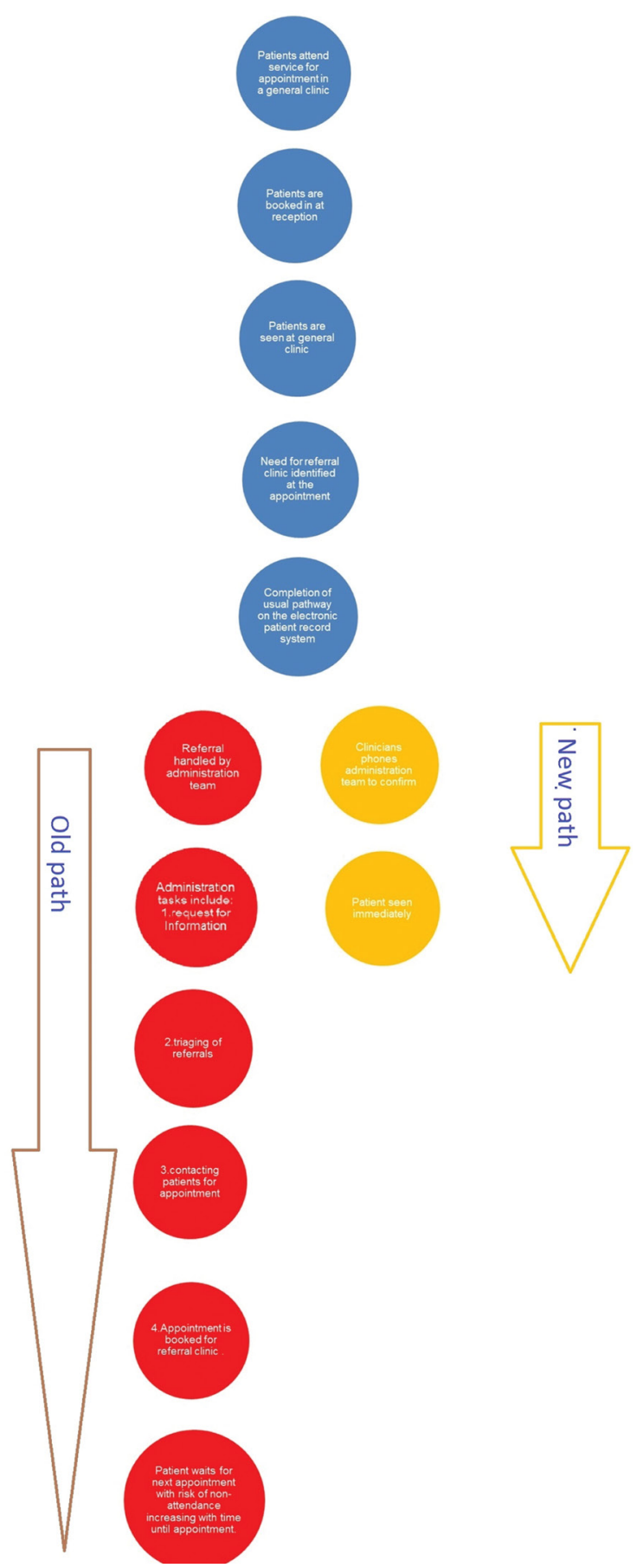

Figure 1 Comparison of patient flows under the two referral systems.

with staff was paramount. Through listening to staff, the logistics of the change could be modified to maximise efficiency. A patient flow template was created (figure 1), outlining inclusion criteria (box 1) and the required procedure for same-day referral. This template was modified through further staff engagement events.

The project was piloted on one day of the week and a number of patients were pre-booked as per the original specialist referral system. This number was modified according to referral rates to maximise efficiency. Referral rates were on average 1.8/day from

\begin{tabular}{ll}
\hline Table 1 Reasons for same-day referrals & \\
\hline Reason for referral & $\mathbf{n}$ \\
\hline Abdominal pain or bleeding with IUC & 17 \\
$\begin{array}{l}\text { IUC non-visible threads for confirmation of IUC in situ and } \\
\text { correctly positioned }\end{array}$ & 13 \\
\hline Failed IUC removals & 5 \\
\hline $\begin{array}{l}\text { Query of failed early medical termination of pregnancy/ } \\
\text { retained product for IUC removal or TVS }\end{array}$ & 2 \\
$\begin{array}{l}\text { Failed IUC insertion } \\
\text { Long or short thread of IUC }\end{array}$ & 1 \\
\hline Deep implant removal & 1 \\
\hline Inappropriate referral & 1 \\
\hline IUC, intrauterine contraceptive; TVS, transvaginal ultrasound scan. & 1 \\
\hline
\end{tabular}

within the MPC (internal referrals) and 2.8/day to the MPC (external referrals). Implementing the system on another day of the week proved to be unsuccessful due to a more rigid timetable on that day.

\section{WHAT WERE THE FINDINGS?}

The pilot project ran for 8 months between May and December 2015. There were 41 same-day referrals over the period, with a maximum of three per day. All were seen on the day of their referral. There was a variety of reasons for referral, the most common being non-visible intrauterine device (IUD) threads or failed removal.

The reasons for referral are shown in table 1.

\section{Box 1 Inclusion criteria}

- Women with an IUC and non-visible threads:

- For confirmation of position only

- Requesting removal and replacement with an IUS and no risk of pregnancy

- Requesting removal and replacement with an IUD and not be at risk of pregnancy or be eligible for EC IUD.

- Suspected IUC malposition on the basis of shorter or longer threads since insertion $+/-$ recent symptoms of pain or bleeding. If malposition identified, patients offered immediate replacement as clinically appropriate.

- Assessment and removal of deep implants.

- Insertion of an IUC and a history of fibroids or cervical surgery or previously failed insertion.

- Women with migraine requesting hormonal contraception.

- Women with coincidental medical conditions where consultant input will alter the outcome for the patient that day.

EC, emergency contraception; IUC, intrauterine contraceptive; IUD, intrautereine device; IUS, intrauterine system. 
COMPARISON OF OLD AND NEW REFERRAL SYSTEMS

During an audit period of 1 year (2015), a total of 923 patients were referred for Level 3 assessment under the original system, of whom 863 (91\%) were new patients, with 627 (74\%) referred internally. Patients were defined as new if they were seen in a Level 3 (referral clinic) for the first time. The other $236(26 \%)$ of the new patients were external referrals from other healthcare providers who were mostly general practitioners; these women were excluded from the analysis of this study. There was an $11 \%$ DNA rate and $18 \%$ of women needed to use additional contraception while waiting for their referral appointments.

Since the new referral system was limited to a maximum of three same-day referrals per session, both the old and new referral systems ran concurrently during the pilot, which allowed us to compare activity between the two systems.

During the new system of referral, staff referred an average of two to three patients to the same-day service on each day that it was available. The new system significantly reduced the heavy administrative costs of contacting patients to arrange additional appointments for specialist care. By definition, for patients referred and seen on the same day, there was no need for additional communication between the patient and the administrative team. In contrast, on average three administrative contacts were necessary with patients referred from the MPC on other days in the original system, and four if patients were referred from satellite clinics. Both groups had on average two face-to-face or telephone consultations until they were seen in the referral clinic.

Most (85\%) of the 625 internally referred new patients had their care completed on the same day, and $15 \%$ needed a follow-up appointment. The time to complete patients' specialist care was on average 4 days for patients seen on the same day, but 46 days for patients referred from the MPC and 41 days for patients referred from satellite clinics. The total DNA rate for the first appointment was $8.3 \%$ under the original referral system, with a maximum of $12 \%$ for patients who waited longer than 4 weeks, whereas

\begin{tabular}{lccc}
\hline Table 2 & \multicolumn{3}{l}{ Attendance by waiting times } \\
\hline Group & Attended (\%) & Cancelled (\%) & $\begin{array}{l}\text { Did not attend } \\
(\%)\end{array}$ \\
\hline Same day & 100.0 & 0.0 & 0.0 \\
\hline 1-7 days & 89.7 & 6.9 & 3.4 \\
\hline 8-14 days & 83.0 & 12.8 & 4.3 \\
\hline 15-28 days & 84.1 & 10.8 & 5.2 \\
>28 days & 73.4 & 14.5 & 12.0 \\
\hline Total & 79.8 & 12.0 & 8.3 \\
\hline
\end{tabular}

there were no DNAs for patients seen on the same day under the new referral system. (table 2)

\section{STAFF VIEWS}

The pre-change and post-change staff survey, which was completed by administrative and clinical staff, suggested that this change was highly acceptable for staff; 44/150 staff responded to the survey, with $97 \%$ agreeing that patients should be seen within 1-2 weeks and $71 \%$ agreeing that the option to be seen on the same day should be provided. Most staff did not feel that the current waiting times were acceptable. The following staff comments were received:

\begin{abstract}
It is really satisfying to be able to offer a referral clinic appointment on the same day - it's clear that patients have come in with a concern and to be able to resolve it so swiftly is clearly better for everyone. In the instance where other history/results need to be gathered [this] justifies a wait for [an] appointment, otherwise [there is] no real justification.

There are a small number of patients who could benefit from being seen quickly in the referral clinic; for example, patients with non-visible threads who wish to continue with their IUD/IUS. Sometimes having a small waiting period does help as their symptoms get better within that time, which in fact reduces the need for any other intervention.-

Patients do understand and accept that when they have complex needs there will be a waiting period.
\end{abstract}

\section{COSTS}

Based on this relatively small pilot study, we estimated that $£ 24740$ could be saved over 12 months (calculated with BMJ cost saving calculator see supplementary file 1) by avoiding additional phone calls and visits, and the costs of patients' non-attendance. As illustrated by some of the staff views (above), a potential disadvantage of the new referral system may arise if there is a low threshold for referral leading to unnecessary intervention. It is therefore important to have clear referral criteria.

\section{CHANGES TO THE SERVICE AS A RESULT OF THE PROJECT}

The Service Standards of the Faculty of Sexual $\&$ Reproductive Healthcare ${ }^{6}$ recommend providing a Level 3, consultant-led SRH service "per population of 125000 to ensure adequate quality of service provision, training, clinical governance and risk management across all three levels of service provision".

The MPC has provided specialist services including ultrasound for more than 20 years. Such services have been well received and described as 'very acceptable' by patients. $^{7}$

However, under the original referral system, non-attendance rates increased with the duration of waiting time for an appointment. Moreover, $18 \%$ of patients needed bridging methods of contraception 
while waiting for an appointment, which could lead to increased risk of unintended pregnancy. The new service offered more effective, patient centred care. We gained a clear impression that patient experience improved, although very low completion rates of the patient survey did not enable this to be evaluated formally. As a result of this pilot, we have implemented two open appointments every day at the MPC, with a maximum of 10 per week, so that patients can be referred for a specialist opinion on the same day.

Acknowledgements We are grateful to all the patients and staff of the Margaret Pyke Centre for their involvement in this project. Kate Hedge, Helen Prime and her great admin team deserve mention. Special thanks to Ian Kirkwood for providing data on attendances and project support. Dr Chris Wilkinson contributed to the planning of the work described in this article.

Contributors SM and JMS contributed to the planning, conduct and reporting of the work described here. US moved to London North West Healthcare NHS Trust in August 2017. SM undertook this work as part of her fixed-term post as Knowledge Mobilisation Fellow at the London National Institute of Health Research, University College London.

Funding The first-named author received a Margaret Pyke Trust Award for this project.

Competing interests None declared.

Provenance and peer review Not commissioned; externally peer reviewed.

(c) Article author(s) (or their employer(s) unless otherwise stated in the text of the article) 2018. All rights reserved. No commercial use is permitted unless otherwise expressly granted.

\section{REFERENCES}

1 Department of Health. A framework for sexual health improvement in England. https://www.gov.uk/government/ uploads/system/uploads/attachment_data/file/142592/92872900714-TSO-SexualHealthPolicyNW_ACCESSIBLE.pdf (accessed 21 Jul 2017).

2 The King's Fund. Public satisfaction with the NHS. http://www. kingsfund.org.uk/projects/public-satisfaction-nhs (accessed 1 Jan 2016).

3 NHS England. NHS England using technology to beat cost of missed appointments. https://www.england.nhs.uk/2014/03/ missed-appts/ (accessed 1 Jan 2016).

4 Department of Health and Social Care. A zero cost way to reduce missed hospital appointments. https://www.gov. uk/government/publications/reducing-missed-hospitalappointments-using-text-messages/a-zero-cost-way-to-reducemissed-hospital-appointments (accessed 1 Jan 2016).

5 Langley GL. The Improvement Guide: A Practical Approach to Enhancing Organizational Performance. 2nd edn. San Francisco: CA: Jossey-Bass Publishers, 2009. ISBN: 978-0- 47019241-2.

6 Faculty of Sexual \& Reproductive Healthcare (FSRH). FSRH service standards for sexual and reproductive healthcare September 2016. http://www.fsrh.org/standards-and-guidance/ documents/fsrh-service-standards-for-sexual-and-reproductivehealthcare/and https://www.fsrh.org/news/updated-servicestandards-for-sexual-and-reproductive/ (accessed 1 Jan 2016).

7 Jawad R, Robinson G. Gynaecological ultrasound in community sexual and reproductive health clinics. J Fam Plann Reprod Health Care 2009;35:35-7. 